\title{
Affective influences on energy-related decisions and behaviors
}

\author{
Tobias Brosch ${ }^{1,2}$ *, Martin K. Patel ${ }^{3,4}$ and David Sander ${ }^{1,2}$ \\ 1 Department of Psychology, University of Geneva, Geneva, Switzerland \\ ${ }^{2}$ Swiss Center of Affective Sciences, University of Geneva, Geneva, Switzerland \\ ${ }^{3}$ Energy Group, Institute for Environmental Sciences, University of Geneva, Geneva, Switzerland \\ ${ }^{4}$ Energy Group, Forel Institute, University of Geneva, Geneva, Switzerland
}

Edited by:

Joni Jupesta, United Nations

University, Japan

Reviewed by:

Antonio Scala, Consiglio Nazionale

delle Ricerche, Italy

Masaru Yarime, University of Tokyo,

Japan

${ }^{*}$ Correspondence:

Tobias Brosch, Department of

Psychology, University of Geneva, 40,

Boulevard du Pont d'Arve, Geneva

$\mathrm{CH}-1205$, Switzerland

e-mail: tobias.brosch@unige.ch
A successful energy transition will depend not only on the development of new energy technologies, but also on changes in the patterns of individual energy-related decisions and behaviors resulting in substantial reductions in energy demand. Across scientific disciplines, most theoretical approaches that try to understand energy-related decisions and behaviors focus mainly on cognitive processes, such as computations of utility (typically economic), the impact of cognitive heuristics, or the role of individual beliefs. While these models already explain important aspects of human decisions and behavior in the energy domain, we argue that an additional consideration of the contributions of emotional processes may be very fruitful for a deeper understanding of the issue. In this contribution, we outline a theoretical perspective on energy-related decisions and behaviors that integrates emotions, elicited by a cognitive-affective appraisal of the relevance of a situation, into a response system driving adaptive decisions and behaviors. We empirically investigate the explanatory power of the model variables to predict intentions to reduce energy use demonstrating that the appraisal-emotion variables are able to account for additional variance that is not explained by two established models focused on cognitive processes (theory of planned behavior and value-belief-norm theory). Finally, we discuss how the appraisal-emotion approach may be fruitfully integrated with other existing approaches and outline some questions for future research.

Keywords: affect, behavior, energy, decision-making, emotion

\section{INTRODUCTION}

An increasing number of countries have implemented policies targeting the increased use of renewable energy sources, improved energy efficiency, and the abatement of greenhouse gas emissions. The success of this energy transition will depend not only on the development of new energy technologies, but also on major changes in the patterns of individual energy-related decisions and behaviors resulting in substantial reductions in energy demand. To an increasing extent, this is being acknowledged by science and stakeholders. The Stern Review on the Economics of Climate Change, for example, points out the removal of barriers to behavioral change as one of three essential elements of energy and climate policy (next to carbon pricing and technology policy; Stern, 2007). It is thus of crucial interest for society and policy makers to gain an understanding of the underlying factors and mechanisms that drive these decisions and behaviors.

Given the importance of the issue, several disciplines of the behavioral sciences have advanced theoretical frameworks that aim to identify target variables for potential interventions to reduce energy demand (see Wilson and Dowlatabadi, 2007 for a review). For example, classic microeconomic approaches focus on the "rational actor" model, which assumes that people make their decisions by comparing the utility of the different available options and by choosing the outcome with the highest utility, while having access to all the important information that is needed for a rational decision (Becker, 1976). In their decisions, people are assumed to act based on preferences that are known to them, invariant and consistent, and always aiming at the maximization of their utility. Utility is often expressed in monetary terms, and interventions that aim at changing energy-related decisions and behaviors are mainly focusing on changes in price structures (e.g., increasing energy prices), which result in an increased utility of reducing one's energy use (Tietenberg, 1990). More recently, approaches from the field of behavioral economics have gained popularity. They take into account empirical observations showing that individuals' decisions are not always based on rational deliberations, but are subject to a number of cognitive shortcuts and biases (Kahneman, 2003). For example, people tend to be overly influenced by cognitive anchors (e.g., the status quo; see Samuelson and Zeckhauser, 1988) or by the framing of the choice situation (e.g., whether it emphasizes potential losses or gains; see Tversky and Kahneman, 1981). These biases can be exploited when decision situations are designed in a certain manner in order to "nudge" people toward decisions and behaviors that reduce energy use (Thaler and Sunstein, 2008), e.g., by changing default settings on household appliances to less energy-intensive programs.

Whereas economic approaches mainly focus on aspects of the decision situation, especially the underlying incentive structure, psychological approaches emphasize the importance of internal factors on the side of the decider, such as belief structures, value 
systems, attitudes, or norms (Ajzen, 1991; Stern, 2000). Individual differences in, for example, beliefs about the causes or the importance of climate change or explicit attitudes toward energy conservation are considered important drivers of energy-related decisions. Interventions based on these approaches may include strategies that aim at changing people's beliefs or attitudes (Cialdini, 2009) in order to promote reductions in energy use, and may be tailored to specific groups of people (such as people with high environmental values, see, e.g., Sutterlin et al., 2011).

Across disciplines, most theoretical approaches that try to understand energy-related decisions and behaviors focus exclusively on cognitive processes. Computations of utility, the impact of cognitive heuristics, or the role of individual beliefs and social norms are considered the main drivers of relevant decisions. Only a few theories take into account the role of affective processes and emotions (see, e.g., Kals and Muller, 2012). If these processes are considered, they are often conceptualized as biases that interfere with rational thinking. For example, peoples' judgments about the risks and benefits of nuclear energy are explained by their initial affective responses and gut feelings (Finucane et al., 2000); intensive car use is explained by strong emotional attachment to the car (Marsh and Collett, 1986). Emotions are thus reduced to an irrational bias that leads to suboptimal decisions that are not in the best interest of the individual or the environment.

The view of emotions as an irrational force that opposes cognition and reasoned thought dominated in philosophy for many centuries (see, e.g., the writings by Plato or Descartes), and still today survives in many academic disciplines as well as in lay theories of emotion. However, over the last two decades, psychological and neuroscientific research on emotions has made great strides toward a revision of this conceptualization. Recent theories on the functioning of emotions consider emotion and cognition not as separate, opposing entities, but as strongly intertwined and complementary (Scherer, 2009; Brosch, 2013; Sander, 2013). Cognitive appraisal processes that automatically and continuously evaluate our environment to detect relevant information play a crucial role in the elicitation of emotions. Emotional responses carry important information about the value of objects or events in our environment, and help us focus on the most important aspects of the surrounding environment by adaptively modulating our cognitive systems (Brosch et al., 2013). Affective processes and emotions thus should not be considered as irrational forces that are counterproductive to our decision-making, but to the contrary as processes yielding important information that, together with cognitive considerations, can help us make very "rational" (i.e., adaptive and useful) decisions. Given the fundamental interest of society to understand energy-related decisions and behaviors, it may be fruitful and important to take into account affective and emotional processes, as they may contribute to a better understanding of the underlying mechanisms, improved predictions of the resulting choices and behaviors, as well as potential leverage for more effective interventions.

In this contribution, we outline a theoretical perspective on energy-related decisions and behaviors based on these recent theoretical developments ${ }^{1}$. In this perspective, emotional

${ }^{1}$ Note that the perspective outlined here primarily addresses the individual citizen in his/her role as final user of energy. responses are integrated into a response system that drives adaptive decisions and behaviors based on a cognitive-affective evaluation. We begin by summarizing and discussing current developments in emotion psychology and neuroscience that describe how the perspective regarding the functionality (or "rationality") of emotion has changed over the last few decades ("affective turn"). We then describe two of the most influential theoretical models that have previously been used to explain energy-related decision-making and behavior, the theory of planned behavior (TPB, Ajzen, 1991) and the value-belief-norm theory (VBN, Stern, 2000). While these models already explain important aspects of human decisions and behavior in the energy domain, we argue that an additional consideration of the contributions of emotional processes may be very fruitful for a deeper understanding of the topic. To this end, we outline a perspective describing how appraisal processes and emotions may inform decisions and behaviors in the energy domain. We then present empirical data that compares the explanatory power of our appraisal-emotion approach with the two established psychological theories TPB and VBN in order to evaluate whether our approach can add explanatory value to the prediction of intentions to reduce energy use. Finally, we discuss how the appraisal-emotion approach may be fruitfully integrated with other existing approaches and outline some questions for future research.

\section{THE RELATIONSHIP OF COGNITION AND EMOTION}

Beginning with Plato, philosophers have often characterized the functioning of the human mind as a battle between opposing forces: reason, rational, and deliberate versus emotion, impulsive, and irrational (Goldie, 2010). This thinking has also been reflected in psychological theories and research on emotion: emotions were considered as interference that is counterproductive for a correct functioning of cognitive mechanisms, and thus perception, attention, memory, or decision-making were investigated without taking into account the effects of emotion. After a long time of neglect, however, the last two decades have seen an enormous increase in research on emotion highlighting the importance of emotional processes for a successful functioning of the human mind (Davidson et al., 2003; Sander and Scherer, 2009).

For example, neuropsychological studies have shown that patients with brain lesions that cause emotional dysfunctions can be highly impaired in everyday decision-making and social interactions (Damasio, 1994). These patients show inappropriate actions that lead to financial losses, to losses in social standing, and to conflicts with their family and friends. They also show a substantially reduced emotional reactivity to many types of events and a very limited interoception of their bodily responses, whereas their rational problem-solving abilities remain largely intact. These observations have led to the hypothesis that emotions may play an important role in shaping and guiding adaptive decisions. In a series of experiments, it has been shown that during their decision-making, these patients are not able to integrate emotional signals from the body that are triggered when one is about to make risky decisions (Bechara et al., 1997). These emotional signals are thought to represent learned experiences from previous decisions, which can be integrated to inform current choices, e.g., by helping to reject disadvantageous options (Bechara et al., 2005). 
The adaptiveness of emotional responses has furthermore been demonstrated in economic experimentations, where individuals participate in financial exchanges in small groups. In some of these economic games, a participant has the opportunity to spend some of his money to punish other participants for unfair behavior, such as failing to share a profit from a financial transaction. At the group level, these punishments are highly effective for keeping up fair interactions, and social groups whose members are willing to punish unfair behavior function much better in the long run (Fehr and Gachter, 2002). In order to punish, however, the punishing person has to sacrifice a part of his or her own profit, which is highly inconsistent with economic theories of utility maximization. Neuroimaging studies have shown that the observation of unfair behavior is accompanied by activation of the insula, a brain region involved in the experience of aversive emotional states (Sanfey et al., 2003), while a costly punishment of unfair behavior is associated with an activation of regions of the brain's reward system (de Quervain et al., 2004). This suggests that the perception of someone else's unfair behavior (that is beneficial for the individual, but damaging for the group in the long run) triggers aversive emotional responses, while punishing this behavior is perceived as rewarding even though it involves financial losses. These emotional reactions ensure long-term collaboration at the group level and are thus more "rational" than decisions that are purely based on economic utility maximization.

In parallel to these neuropsychological demonstrations, recent theoretical developments in emotion psychology have abolished the strong opposition of cognition and emotion, but instead emphasize that emotional and cognitive processes are strongly intertwined. Appraisal theories of emotion claim that emotions are elicited as the individual automatically and continuously evaluates the information in one's environment, scanning for information that is relevant to one's concerns, goals, needs, and values (Ellsworth and Scherer, 2003; Moors, 2010). Psychological and neuroimaging research has helped to specify the evaluation criteria that are involved in the appraisal process, showing that the appraisal process is composed of very rapid automatic low-level processes as well as slower, more deliberate processes that together evaluate any incoming stimulus regarding the following criteria: relevance (does this directly affect me), implications (what does it mean for my well-being), coping potential (can I deal with the challenge), and congruency with moral considerations (is this appropriate with regards to my values and personal norms; see, e.g., Grandjean and Scherer, 2008; Moors, 2010; Brosch and Sander, 2013a; Gentsch et al., 2013).

The integrated outcome of this appraisal process determines the type of emotional response that is elicited (Siemer et al., 2007). For example, an appraisal of a situation as threatening and uncontrollable will trigger a fear response including motivational changes (a tendency to withdraw), physiological changes (increases in heart rate), changes in expression (eyes wide open), and changes in one's subjective feeling (experiencing fear), thus mobilizing the resources required to escape from the situation. A key notion of appraisal theories is that, given that the emotion is elicited based on an analysis of the situation that takes into account the requirements of the situation and the coping potential of the individual, emotional responses will be adaptive in their fit to the situational challenge. To illustrate, in contrast to the previous example of a threat that is appraised as uncontrollable and elicits fear, an obstruction that is appraised as controllable will rather elicit an anger response consisting of a tendency to attack, an increase in blood pressure, contracted eyebrows, and the experience of anger (Kreibig, 2010), thus enabling the individual to remove the obstacle.

The detection of relevant environmental information furthermore leads to a fundamental reorganization of a number of cognitive systems in order to prioritize the processing of the relevant information. For example, emotionally relevant information is automatically privileged by our perceptual and attentional systems, thus allowing the information to be noticed rapidly and, once detected, become the focus of further processing and action (Vuilleumier and Brosch, 2009). Furthermore, emotional information is prioritized in memory. Memories of emotional events are encoded and consolidated more deeply, and have a persistence and vividness that other memories seem to lack (Phelps and Sharot, 2008). Given that they represent events that have been appraised as especially relevant (Montagrin et al., 2013), emotional memories may serve as useful guides for future behavior. Emotion thus operates as an adaptive filter for incoming information focalizing our cognitive processing on information that is relevant to our concerns, goals, needs, and values, and thus setting the stage for subsequent behavior.

As illustrated by the examples in the previous sections, emotions can be important drivers of our decision-making, over and above cognitive factors and computations of utility alone. Effects of emotions on decisions can occur at different time horizons. For example, an emotion that is elicited in a concrete situation may be used as indicator of the relevance of the situation and lead to an appropriate decision (e.g., the indignation elicited by seeing a heavily polluted pond may motivate you to immediately sign up for a donation to Greenpeace). Alternatively, your anticipation of a future emotion may impact on your decision between several options (e.g., when deciding whether or not to buy a hybrid car, you may think about the pride or satisfaction that the status related to owning such a car may elicit and weigh it against the potential disadvantages). These two influences are referred to as effects of immediate emotions and anticipated emotions, respectively (Han and Lerner, 2009) $)^{2}$.

Two important points result from this review of current developments in the emotion literature: (1) emotions emerge from a rapid and automatic cognitive-affective analysis of the situational challenges as well as the individual's potential to deal with them, and thus very often are adaptive, intelligent responses that reflect useful information. (2) Emotions play a big role in human decision-making and hence drive behavior, and an analysis of appraisal patterns and emotional responses may yield important insights into individual choices and behaviors. While a consideration of affective processes may also be very informative for explaining energy-related decisions and behaviors, the most influential

\footnotetext{
${ }^{2} \mathrm{~A}$ third type of emotional effect on decision-making involves so-called incidental emotions, which are emotions that arise from factors not related to the decision at hand. For example, you refuse to make a donation to Greenpeace because you are angry about an unrelated discussion you had with your boss earlier.
} 
theories used in this field so far do not consider these factors as important drivers of human behavior.

\section{CURRENT THEORIES OF ENERGY-RELATED DECISIONS AND BEHAVIOR}

The TPB (Ajzen, 1991) is the theoretical framework that is most widely used in attempts to explain individual energy-related decisions and behaviors. TPB assumes that a behavior is the consequence of a reasoned process that weighs the costs and benefits of the behavior. An individual's intention to perform a certain behavior (which is the most important predictor of the actual behavior) is thought to be determined by three main factors: the individual's attitude toward the behavior (reflecting the explicit evaluation of a behavior, based on a weighing of various costs and benefits such as financial costs, effort, time, and potential profit), the individual's perceived behavioral control (referring to the ease or difficulty with which the individual can engage in the behavior), and subjective norm (an individual's perception of the extent to which important social reference persons such as friends, family, or colleagues would approve or disapprove of the behavior as well as the individual's motivation to comply with these social pressures). TPB has been successfully used to predict and explain a wide range of behaviors, including energy-relevant behaviors such as energy savings (Harland et al., 1999) or choice of transportation (Bamberg et al., 2003). A meta-analysis of studies using TPB found that the factors postulated by the theory explained 39\% of the variance of intentions and $27 \%$ of the variance of actual behaviors (Armitage and Conner, 2001). As a "rational choice" theory, TPB conceptualizes individual decisions as driven by cognitive processes underlying self-interested utility maximization, and does not consider affective processes or emotions as important drivers of decisions ${ }^{3}$.

While TPB is centered on the maximization of self-interest (including conformity with subjective external norms), the VBN (Stern, 2000) and its predecessor, the norm activation model (NAM, Schwartz, 1977) have been developed with the explicit aim to explain altruistic behavior. According to NAM, behavior is driven by an individual's personal norms, referring to a feeling of moral obligation to perform a certain behavior. This moral obligation results from an awareness of a problem and its potential consequences as well as the belief that one can do something to avert these consequences. Based on this idea, VBN has been specifically developed to explain environmental behaviors. VBN proposes a causal chain of variables that has its starting point with an individual's core values. These values, which are broad representations of an individual's overarching goals, in turn determine an individual's environmental beliefs, which describe how an individual sees himself or herself in relation to the environment. Environmental beliefs are related to the extent to which individuals think that their own behavior can have negative consequences for the environment (awareness of consequences), which in turn determines whether an individual assumes responsibility

\footnotetext{
${ }^{3}$ Even though a factor of the theory is labeled "attitude," a concept frequently used in emotion psychology, the attitude construct used in TPB is a very cognitive one, based on the weighing of the potential costs and benefits of the action ("How many positive and negative consequences do I expect from this behavior"), and as such very close to the economic concept of utility.
}

for environmental problems (ascription of responsibility). Assumed responsibility results in the activation of a moral obligation to act (personal norms), which is positively related to the willingness and intention to act pro-environmentally. VBN has been used to successfully predict a number of environmentally related decisions and behaviors, such as intentions to reduce car use (Nordlund and Garvill, 2003) or to recycle (Guagnano et al., 1995). In general, its predictive power seems to be higher for intentions than for actual behaviors (Lindenberg and Steg, 2007).

The theoretical framework of the VBN with the postulated causal chain of factors emphasizes cognitive factors such as beliefs and norms. Affective processes or emotions are not explicitly included into the driving factors of decisions and behaviors. Interestingly, the VBN emphasizes the importance of core values, which play a key role in the elicitation of emotions (Nelissen et al., 2007) and their role in decision-making (Brosch and Sander, 2013b). Furthermore, personal norms, reflecting the moral obligation to act environmentally, are often assessed using items with an emotional content such as "I feel guilty when I use a lot of energy" (Abrahamse and Steg, 2009). Thus, at least implicitly emotions are included here, but their role is not explicitly spelled out in the theory.

Taken together, the two dominant psychological theories that are used to explain energy-related decisions and behavior are mainly centered on cognitive variables and mechanisms. TPB is a rational choice theory focusing on expectancy $\times$ value computations that maximize self-interest, while $\mathrm{VBN}$ is a normative theory combining value and belief systems into internal obligations about the "right thing to do." Given the recent advances in theorizing on emotion, we feel that it may be worthwhile to attempt an integration of affective processes into models that aim to explain energy-related decisions and behaviors.

\section{AN APPRAISAL-EMOTION PERSPECTIVE ON ENERGY-RELATED DECISIONS AND BEHAVIORS}

Energy-related decisions and behaviors are most likely driven by a combination of several different factors and motivations, including self-interested considerations (e.g., living in comfort, saving money), social and altruistic motivations (e.g., gaining other's approval, preserving resources for others and future generations), as well as ecological concerns (e.g., reducing damage to nature, see also Lindenberg and Steg, 2007). Appraisal theory holds that emotions reflect the integration of the relevance of an event or object in the context of a person's concerns, goals, needs, and values. Emotional processes and emotional experience may thus be an appropriate mechanism for the integration of several classes of motivational considerations (which may even be in conflict with each other).

Here, we propose a theoretical approach that integrates an analysis of cognitive appraisals concerning the relevance of energy conservation as well as emotions that are experienced in situations that are related to energy conservation. In order to develop a parsimonious, theory-driven approach, we based the model on a body of research on appraisal processes that has identified the psychological and neural mechanisms underlying the main classes of appraisals that play important causal roles in the elicitation of emotion (Ellsworth and Scherer, 2003; Brosch and Sander, 2013a), 
and specified the appraisal classes by adapting them to the thematic of energy conservation. The model thus predicts that the following appraisals are important for the elicitation of emotions as well as for the prediction of important individual differences in energy-related decisions and behaviors:

1. Relevance: To what extent am I affected by the problem of climate change?

2. Implication: How immediate is the impact of these changes on my life?

3. Coping potential: To what extent can I contribute to the prevention of these changes by saving energy?

4. Value-congruence: To what extent is energy conservation desirable in the context of my value hierarchy?

Different people will appraise the same situation differently as a function of their concerns, goals, needs, and values, and will thus react with different emotional responses to these situations. An individual's appraisal profile should predict the frequency and/or intensity of an individual's emotional reactions in relevant situations, such as pride when successfully conserving energy, or indignation when observing someone else waste energy. Finally, both the pattern of an individual's appraisal and the pattern of an individual's emotional reactivity in relevant situations should be useful predictors of an individual's intention to engage in energy-saving behaviors.

Our aims in this contribution are twofold: (1) to move toward a theoretical integration of cognitive and affective processes into models that are used to explain energy-related decisions and behaviors. Even though at least one psychological model widely used in applied research (VBN) already implicitly includes affective factors (such as values and moral emotions), the role of emotion is not explicitly included in most models. Here we aim at developing this theoretical integration, taking into account the most recent developments in emotion psychology. Importantly, we wish to move beyond the perspective of emotion as an "irrational interference," but to offer a clear integrative theory that describes the interplay of cognition and emotion and emphasizes the functional, adaptive aspect of emotional responses. (2) To empirically evaluate the potential contributions of our appraisal-emotion approach to the explication of individual intentions to reduce energy use, and especially to evaluate whether our approach can explain parts of the variance of individual decisions and behaviors that are not taken into account by mainly cognitive models focused on self-interest (TPB) or normative considerations (VBN), and thus may offer new and additional insight into the factors underlying energy-related decisions and behaviors that are consequential for a successful energy transition.

We compared the predictive power of three psychological theories that have postulated sets of variables in order to explain individual intentions to reduce energy use: the TPB, the VBN, and the appraisal-emotion approach introduced here. In the first step, we test the predictive power of each of the three theories separately. In the second step, we combine the different models using hierarchical regression analysis, to test whether the appraisal-emotion model can explain any additional variance, or whether the proposed factors are already sufficiently captured by the established models.

\section{MATERIALS AND METHODS PARTICIPANTS}

A total of 168 students of the University of Geneva (146 females, 22 males, mean age: 22.1 years, SD: 4.6) participated in the study.

\section{MEASUREMENTS}

We designed a number of questionnaires to measure the key variables postulated by the different theories. Given that numerous studies already tested the degree to which TPB and VBN predict energy-related decisions and behaviors (see, e.g., Poortinga et al., 2003, 2004; Abrahamse and Steg, 2009, 2011), we adapted our measures from these publications.

\section{Theory of planned behavior}

Attitude toward energy conservation was measured using several semantic differential scales ("bad-good," "unnecessary-necessary," "positive-negative," "not fun-fun," "important-unimportant," and "useless-useful") that were combined into one score. Perceived behavioral control was measured by three items ("I know how I can save energy in daily life," "I find it difficult to reduce my energy use," and "I can reduce my energy use quite easily") combined into one score. Subjective norms were measured by combining two items ("My family members think it is important that I conserve energy" and "My close friends think it is important that I conserve energy") into one score. All responses were assessed using seven-point Likert scales.

\section{Value-belief-norm theory}

Participants' value priorities were measured using the Schwartz Value Inventory (SVI, Schwartz, 1992). Participants rated 57 items covering 10 different types of values (power, achievement, hedonism, stimulation, self-direction, universalism, benevolence, tradition, conformity, and security) on a nine-point scale from opposed to my principles $(-1)$ through not important (0) to of supreme importance (7). Individual scores for the second-level value dimensions self-enhancement, self-transcendence, openness to change, and conservatism were then formed by averaging scores across the respective value types. Beliefs were assessed using the revised version of the new environmental paradigm (NEP, Dunlap et al., 2000) as well as five items measuring awareness of consequences ("The greenhouse effect is a problem for society," "The increasing energy demand is a serious problem for our society," "Energy conservation contributes to a reduction of the greenhouse effect," "The depletion of fossil fuels is a problem," and "Claims that we are changing the climate are greatly exaggerated," combined into a single score), and one item measuring ascription of responsibility ("I take joint responsibility for the depletion of energy resources"). Personal norms were assessed by three items: "I feel guilty when I choose a mean of transportation with high energy consumption (e.g., plane) even though there is an energy-friendlier travel option (e.g., train)," "I have a bad conscience when energy is consumed unnecessarily in the household (e.g., lights on in unused rooms)," and "I have a bad conscience when I buy, e.g., strawberries from South Africa in the winter instead on seasonal fruit from the 
region," combined into a single score). All responses were assessed using seven-point Likert scales.

\section{Appraisal-emotion theory}

We measured key appraisal and emotional variables pertinent to our appraisal-emotion approach with a newly developed set of items. Relevance appraisal was measured using the item "How close or distant do you feel as an individual to the problem of climate change (very distant/very close)?" Implication appraisal was measured using the item "How immediate is the impact of these ecological changes on your life (not at all immediate/highly immediate)?" Coping potential appraisal was measured using the item "To what extent can you contribute to the prevention of climatic change by reducing energy use (not at all/very much)?" Valuecongruence appraisal was measured using the item "To what extent is energy conservation desirable from the perspective of your personal values (not at all desirable/highly desirable)?" All responses were assessed using seven-point Likert scales.

An individual's tendency to experience emotions in situations related to positive or negative ecological behavior was assessed with a series of items ("How often do you feel ashamed because you wasted energy?," "How often do you feel angry because you wasted energy?" "How often do you feel anxious of the consequences of global warming for our planet and its inhabitants?," "How often do you feel indignated because others waste energy?" "How often do you feel contempt because others waste energy?," "How often do you feel ashamed for others because they wasted energy?", and "How often do you feel proud because you have seen others conserving energy or avoiding wasting energy?"). All responses were assessed using five-point Likert scales (ranging from "never" to "very often") and combined into a single score.

\section{Intentions to save energy}

Finally, a set of items measured participants' intentions to engage in energy-saving behavior. Participants were presented with different energy-friendly behaviors (see Table 1, adapted from Poortinga et al., 2003; Poortinga et al., 2004), and indicated their intention to engage in the specific behavior using four-point Likert scales from 1 (not at all) to 4 (definitely). All responses were combined into a single score, where higher scores indicate stronger intentions to engage in energy-saving behavior.

\section{RESULTS}

A series of multiple regression analyses was conducted to evaluate the predictive power of the different theoretical approaches. In a first analysis, we used the variables postulated by TPB (attitude, perceived behavioral control, and subjective norm) to predict intentions to engage in energy-saving behavior (see Table 2). About $34 \%$ of the individual variance in these intentions could be explained by the TPB variables (very similar to the $39 \%$ average variance explained reported in the meta-analysis by Armitage and Conner, 2001). Congruent with theoretical predictions, participants with higher perceived normative pressure, higher perceived behavioral control, and more positive attitudes toward energy conservation had stronger intentions to engage in energy-saving behaviors.

In a second regression analysis, we used the variables predicted by VBN (core values, environmental beliefs, personal norms)
Table 1 | List of energy-saving behaviors covered in the questionnaire (adapted from Poortinga et al., 2003; Poortinga et al., 2004).

Improve house insulation

Use energy-saving light bulbs

Buy more energy-efficient car

Insulate wall behind radiator with heat-reflecting foil

Install more energy-efficient heating system

Buy more energy-efficient refrigerator

Walking or cycling short distances up to $2.5 \mathrm{~km}$

Switching off lights in unused rooms

Line drying of laundry (no dryer)

Do not leave appliances on stand-by

Take shorter showers

Rinsing the dishes with cold water

Walking or cycling distances up to $5 \mathrm{~km}$

Go on holidays by train (instead of plane)

Using public transport

Buy seasonal fruits and vegetables

Set the thermostat to $18^{\circ}$ maximally

Avoid eating meat

Table 2 | Regression results for the TPB variables to predict intentions to engage in energy-saving behavior $(N=168) ; \beta$, standardized regression coefficient; $t, t$-statistic; $R^{2}$, total variance explained; $F$, F-statistic

\begin{tabular}{lcccc}
\hline & $\boldsymbol{\beta}$ & $\boldsymbol{t}$ & $\boldsymbol{R}^{\mathbf{2}}$ & $\boldsymbol{F}$ \\
\hline Subjective norm & 0.235 & $3.28^{* *}$ & & \\
Perceived behavioral control & 0.249 & $3.68^{* * *}$ & & \\
Attitude & 0.304 & $4.39^{* * *}$ & & \\
Model & & & 0.340 & $28.20^{* * *}$ \\
\hline
\end{tabular}

${ }^{* *} p<0.001,{ }^{* *} p<0.01$.

to predict intentions to engage in energy-saving behavior (see Table 3). About $45 \%$ of the individual variance in these intentions could be explained by the VBN variables. Congruent with the theoretically predicted chain of variables (Stern, 2000), personal norms as the most proximal variable to actual intentions and behavior was the most powerful (and the only significant) predictor of energy-related intentions. Additional analyses confirmed the chain of variables predicted by the model: personal norms were strongly correlated with beliefs (NEP: $r=0.36, p<0.001$, awareness of consequences: $r=0.35, p<0.001$, ascription of responsibility: $r=0.40, p<0.001$ ), and beliefs in turn correlated strongly with core values (self-transcendence values correlated with NEP: $r=0.28, p<0.001$ as well as awareness of consequences: $r=0.25$, $p=0.001$; conservation values correlated negatively with NEP: $r=-0.24, p=0.002)$.

To test our appraisal-emotion approach, we then conducted a third regression analysis with the predictor variables relevance appraisal, implication appraisal, coping potential appraisal, valuecongruence appraisal, and experienced emotions (see Table 4). About $39 \%$ of the individual variance in these intentions could be explained by the appraisal-emotion variables, with each individual 
Table 3 | Regression results for the VBN variables to predict intentions to engage in energy-saving behavior $(N=168)$.

\begin{tabular}{lrrrr}
\hline & $\boldsymbol{\beta}$ & $\boldsymbol{t}$ & $\boldsymbol{R}^{\mathbf{2}}$ & $\boldsymbol{F}$ \\
\hline Value: self-enhancement & -0.073 & -0.73 & & \\
Value: self-transcendence & 0.139 & 1.27 & & \\
Value: openness to change & 0.115 & 1.23 & & \\
Value: conservation & 0.029 & 0.27 & & \\
Belief: new environmental & 0.101 & 1.42 & & \\
paradigm & & & & \\
$\begin{array}{l}\text { Belief: awareness of } \\
\text { consequences }\end{array}$ & 0.062 & 0.89 & & \\
$\begin{array}{l}\text { Belief: ascription of } \\
\text { responsibility }\end{array}$ & 0.076 & 1.14 & & \\
Personal norms & & & & \\
Model & 0.468 & $6.46^{* * *}$ & & \\
\hline
\end{tabular}

$$
{ }^{* *} p<0.001
$$

Table 4 | Regression results for the appraisal-emotion variables to predict intentions to engage in energy-saving behavior $(N=168)$

\begin{tabular}{lcccc}
\hline & $\boldsymbol{\beta}$ & $\boldsymbol{t}$ & $\boldsymbol{R}^{\mathbf{2}}$ & $\boldsymbol{F}$ \\
\hline Relevance appraisal & 0.157 & $2.0^{*}$ & & \\
Implication appraisal & 0.126 & $1.95^{+}$ & & \\
Coping potential appraisal & 0.242 & $3.33^{* *}$ & & \\
Value-congruence appraisal & 0.127 & $1.80^{+}$ & & \\
Experienced emotions & 0.231 & $3.10^{* *}$ & & \\
Model & & & 0.394 & $21.02^{* * *}$ \\
\hline
\end{tabular}

${ }^{* *} p<0.001,{ }^{* *} p<0.01,{ }^{*} p<0.05,+p<0.10$.

predictor variable reaching at least marginal statistical significance. Higher appraised relevance, more immediate appraised implications, higher appraised coping potential, higher appraised value congruency, and higher tendency to experience emotions in energy-related situations all independently predicted more intentions to engage in energy-saving behavior. Additional correlational analyses confirmed the postulated link between appraisals and emotions: each individual appraisal variable predicted increases in experienced emotion in energy-relevant situations (relevance: $r=0.49, p<0.001$, implication: $r=0.25, p=0.001$, coping potential: $r=0.40, p<0.001$, value congruency: $r=0.43, p<0.001$ ).

After having established the predictive power of each theoretical approach on its own, in a second step we performed a series of hierarchical regression analyses in order to evaluate whether the variables from the appraisal-emotion approach can explain additional variance over and above the two more established theories $\mathrm{TPB}$ and VBN. We first tested for the combined predictive power of the TPB and the appraisal-emotion variables (see Table 5). When controlling for the TPB factors (which on their own explained 34\% of the variance, see above), appraisal-emotion factors explained a statistically significant additional $13 \%$ of the variance for a combined explained variance of $47 \%$.
Table 5 | Hierarchical regression results for TPB (model 1 ) and the combined variables from TPB and the appraisal-emotion approach (model 2, $N=168$ )

\begin{tabular}{lcccccc}
\hline & $\boldsymbol{\beta}$ & $\boldsymbol{t}$ & $\boldsymbol{R}^{\mathbf{2}}$ & $\boldsymbol{\Delta} \boldsymbol{R}^{\mathbf{2}}$ & $\boldsymbol{\Delta} \boldsymbol{F}$ \\
\hline Model 1 (TPB) & & & 0.340 & 0.340 & $28.16^{* * *}$ \\
Subjective norm & 0.235 & $3.28^{* *}$ & & & \\
Perceived behavioral control & 0.249 & $3.68^{* * *}$ & & & \\
Attitude & 0.304 & $4.39^{* * *}$ & & & \\
Model 2 (TPB and appraisal- & & & 0.469 & 0.129 & 7.70*** \\
emotion approach) & & & & & \\
Subjective norm & 0.136 & $1.99^{*}$ & & & \\
Perceived behavioral control & 0.153 & $2.36^{*}$ & & & \\
Attitude & 0.179 & $2.61^{*}$ & & & \\
Relevance appraisal & 0.097 & 1.29 & & & \\
Implication appraisal & 0.092 & 1.48 & & & \\
Coping potential appraisal & 0.192 & $2.84^{* *}$ & & & \\
Value-congruence appraisal & 0.023 & 0.29 & & & \\
Experienced emotions & 0.180 & $2.48^{* *}$ & & & \\
\hline
\end{tabular}

${ }^{* *} p<0.001,{ }^{* *} p<0.01,{ }^{*} p<0.05$.

We then tested for the combined predictive power of the VBN and the appraisal-emotion variables (see Table 6). When controlling for the VBN factors (which on their own explained $45 \%$ of the variance, see above), appraisal-emotion factors explained a statistically significant additional $8 \%$ of the variance for a combined explained variance of $53 \%$.

In a final analysis, we analyzed the three models together in one hierarchical regression model, with the TPB variables entered in the first step, the VBN variables entered in the second step, and the appraisal-emotion variables entered last (see Table 7). Adding the VBN variables to the TPB variables explained a statistically significant additional $17 \%$ of the variance. Importantly, adding the appraisal-emotion variables to the combined TPB-VBN variables led to another significant increase by $6 \%$ in the explained variance. Taken together, the variable sets from the three theories explained $57 \%$ of the variance in intentions to reduce energy use.

\section{DISCUSSION}

In this manuscript, we propose a framework that applies recent theoretical developments concerning the functionality of affective processes and emotions to the explanation of energy-relevant decisions and behaviors. Based on previous work investigating the impact of appraisal processes on the elicitation of emotion and their impact on decision-making (see, e.g., Damasio, 1994; Han and Lerner, 2009; Brosch and Sander, 2013a,b; Brosch et al., 2013), we proposed that a sparse set of variables consisting of appraisal criteria and emotional experiences in an energy-relevant context may help explain energy-related decisions and behaviors. We empirically investigated the explanatory power of the model variables to predict intentions to reduce energy use and compared the performance of the model to the two most frequently used theories. Initial analyses showed that the variable sets postulated by 
Table 6 | Hierarchical regression results for VBN (model 1) and the combined variables from VBN and the appraisal-emotion approach (model 2, $N=168$ )

\begin{tabular}{|c|c|c|c|c|c|}
\hline & $\beta$ & $\boldsymbol{t}$ & $R^{2}$ & $\Delta R^{2}$ & $\Delta F$ \\
\hline Model 1 (VBN) & & & 0.451 & 0.451 & $16.32 * * *$ \\
\hline Value: self-enhancement & -0.073 & -0.73 & & & \\
\hline Value: self-transcendence & 0.139 & 1.27 & & & \\
\hline Value: openness to change & 0.115 & 1.23 & & & \\
\hline Value: conservation & 0.029 & 0.27 & & & \\
\hline $\begin{array}{l}\text { Belief: new environmental } \\
\text { paradigm }\end{array}$ & 0.101 & 1.42 & & & \\
\hline $\begin{array}{l}\text { Belief: awareness of } \\
\text { consequences }\end{array}$ & 0.062 & 0.89 & & & \\
\hline $\begin{array}{l}\text { Belief: ascription of } \\
\text { responsibility }\end{array}$ & 0.076 & 1.14 & & & \\
\hline Personal norms & 0.468 & $6.46 * * *$ & & & \\
\hline $\begin{array}{l}\text { Model } 2 \text { (VBN and } \\
\text { appraisal-emotion } \\
\text { approach) }\end{array}$ & & & 0.533 & 0.082 & $5.42 * * *$ \\
\hline Value: self-enhancement & -0.047 & -0.50 & & & \\
\hline Value: self-transcendence & 0.161 & 1.56 & & & \\
\hline Value: openness to change & 0.142 & 1.63 & & & \\
\hline Value: conservation & 0.026 & 0.26 & & & \\
\hline $\begin{array}{l}\text { Belief: new environmental } \\
\text { paradigm }\end{array}$ & 0.056 & 0.81 & & & \\
\hline $\begin{array}{l}\text { Belief: awareness of } \\
\text { consequences }\end{array}$ & 0.043 & 0.64 & & & \\
\hline $\begin{array}{l}\text { Belief: ascription of } \\
\text { responsibility }\end{array}$ & 0.041 & 0.66 & & & \\
\hline Personal norms & 0.309 & $3.95^{* * *}$ & & & \\
\hline Relevance appraisal & -0.011 & -0.14 & & & \\
\hline Implication appraisal & 0.115 & $1.96^{+}$ & & & \\
\hline Coping potential appraisal & 0.214 & $3.23^{* *}$ & & & \\
\hline $\begin{array}{l}\text { Value-congruence } \\
\text { appraisal }\end{array}$ & 0.016 & 0.24 & & & \\
\hline Experienced emotions & 0.143 & $1.94^{+}$ & & & \\
\hline
\end{tabular}

${ }^{* *} p<0.001,{ }^{*} p<0.01,{ }^{+} p<0.10$.

the TPB, the VBN, and the appraisal-emotion approach explain similar amounts of variance in intentions to reduce energy use. More importantly, we then showed that when combined in hierarchical regression analyses, the appraisal-emotion variables are able to account for additional variance that is not explained by the established models. This indicates that appraisal and emotion processes may contribute to energy-related decisions over and above considerations based on self-interest maximization and normative concerns. The increase in explained variance was especially pronounced when combining the appraisal-emotion
Table 7 | Hierarchical regression results for TPB (model 1), the combined variables from TPB and VBN (model 2), and the combined variables for TPB, VBN, and the appraisal-emotion approach (model 3, $N=168$ )

\begin{tabular}{|c|c|c|c|c|c|}
\hline & $\beta$ & $t$ & $R^{2}$ & $\Delta R^{2}$ & $\Delta F$ \\
\hline Model 1 (TPB) & & & 0.340 & 0.340 & $28.20^{* * *}$ \\
\hline Subjective norm & 0.235 & $3.28 * *$ & & & \\
\hline $\begin{array}{l}\text { Perceived behavioral } \\
\text { control }\end{array}$ & 0.249 & $3.68 * * *$ & & & \\
\hline Attitude & 0.304 & $4.39 * * *$ & & & \\
\hline \multicolumn{6}{|l|}{ Model 2 (TPB and VBN) } \\
\hline Subjective norm & 0.078 & 1.15 & 0.479 & 0.173 & $6.95 * * *$ \\
\hline $\begin{array}{l}\text { Perceived behavioral } \\
\text { control }\end{array}$ & 0.194 & $3.08 * *$ & & & \\
\hline Attitude & 0.144 & $1.91^{+}$ & & & \\
\hline Value: self-enhancement & -0.064 & -0.66 & & & \\
\hline Value: self-transcendence & 0.098 & 0.91 & & & \\
\hline $\begin{array}{l}\text { Value: openness to } \\
\text { change }\end{array}$ & 0.125 & 1.40 & & & \\
\hline Value: conservation & 0.018 & 0.17 & & & \\
\hline $\begin{array}{l}\text { Belief: new } \\
\text { environmental paradigm }\end{array}$ & 0.047 & 0.65 & & & \\
\hline $\begin{array}{l}\text { Belief: awareness of } \\
\text { consequences }\end{array}$ & 0.070 & 1.01 & & & \\
\hline $\begin{array}{l}\text { Belief: ascription of } \\
\text { responsibility }\end{array}$ & 0.002 & 0.03 & & & \\
\hline Personal norms & 0.374 & $5.17 * * *$ & & & \\
\hline $\begin{array}{l}\text { Model } 3 \text { (TPB and VBN } \\
\text { and appraisal-emotion } \\
\text { approach) }\end{array}$ & & & 0.566 & 0.053 & $3.68^{* *}$ \\
\hline Subjective norm & 0.060 & 0.91 & & & \\
\hline $\begin{array}{l}\text { Perceived behavioral } \\
\text { control }\end{array}$ & 0.141 & $2.25^{*}$ & & & \\
\hline Attitude & 0.126 & $1.71^{+}$ & & & \\
\hline Value: self-enhancement & -0.047 & -0.50 & & & \\
\hline Value: self-transcendence & 0.127 & 1.25 & & & \\
\hline $\begin{array}{l}\text { Value: openness to } \\
\text { change }\end{array}$ & 0.148 & $1.71^{+}$ & & & \\
\hline Value: conservation & 0.014 & 0.14 & & & \\
\hline $\begin{array}{l}\text { Belief: new } \\
\text { environmental paradigm }\end{array}$ & 0.022 & 0.31 & & & \\
\hline $\begin{array}{l}\text { Belief: awareness of } \\
\text { consequences }\end{array}$ & 0.048 & 0.72 & & & \\
\hline $\begin{array}{l}\text { Belief: ascription of } \\
\text { responsibility }\end{array}$ & -0.011 & -0.01 & & & \\
\hline Personal norms & 0.275 & $3.6^{* * *}$ & & & \\
\hline
\end{tabular}


Table 7 | Continued

\begin{tabular}{|c|c|c|c|c|c|}
\hline & $\beta$ & $\boldsymbol{t}$ & $R^{2}$ & $\Delta R^{2}$ & $\Delta F$ \\
\hline Relevance appraisal & -0.023 & -0.31 & & & \\
\hline Implication appraisal & 0.089 & 1.54 & & & \\
\hline Coping potential appraisal & 0.187 & $2.88 * *$ & & & \\
\hline $\begin{array}{l}\text { Value-congruence } \\
\text { appraisal }\end{array}$ & -0.029 & -0.44 & & & \\
\hline Experienced emotions & 0.131 & $1.81^{+}$ & & & \\
\hline
\end{tabular}

${ }^{* * *} p<0.001,{ }^{* *} p<0.01,{ }^{*} p<0.05,+p<0.10$.

variables with $\mathrm{TPB}$, a rational choice theory based on the pursuit of self-interest. But also when combining the appraisal-emotion variables with VBN, which implicitly includes concepts related to affect and emotion, additional variance was explained. Finally, even when controlling for the impact of all variables postulated by TPB and VBN together, the appraisal-emotion variables were still able to explain additional variance in individual intentions to reduce energy use ${ }^{4}$. Taken together, these findings suggest that affective processes and emotions, which have been shown to substantially increase our understanding of a number of different decision processes (Han and Lerner, 2009; Brosch and Sander, 2013b; Brosch et al., 2013), may also constitute a powerful factor determining individual decisions and behaviors in the energy domain.

Intuitively, it should not come as too much of a surprise that the vast spectrum of human decisions and behaviors relevant for the energy consumption of a society (see Table 1 for just a small list of examples) is not only driven by strictly cognitive considerations, but also involves automatic and affectively colored processes. And indeed, some attempts have already been made to more explicitly integrate emotions into psychological theories of environmental behavior (e.g., Triandis, 1977; Kals et al., 1999). However, far less use is made of these theories in current research and intervention development than that made of the two dominant theories TPB and VBN. It may thus be fruitful to attempt an integration of the notion that affective processes and emotions are a valuable source of information for individual decision-making with existing models that focus on other drivers of decisions and behavior, such as the incentive structure of the situation, individual self-interest, or normative considerations. By combining recent insights about the functionality of emotions with already existing approaches, this perspective may become more interesting for scientists from other academic traditions and potentially also for policy makers searching for effective interventions. Interdisciplinary integration is highly desirable for tackling a problem as complex and important as the behavior change necessary for a successful energy transition, as approaches that are rooted within the conceptual

\footnotetext{
${ }^{4}$ Note that even with the most complete model, a substantial portion $(43 \%)$ of the individual variance in behavioral intentions to reduce energy use remains unaccounted for. Additional psychological (e.g., implicit biases, personality traits) or non-psychological (e.g., socio-economic status, individual situational constraints) factors that were not assessed in this investigation may furthermore contribute to the formation of individual behavioral intentions.
}

boundaries of one discipline can only hope to capture a small part of the whole process.

Energy-related decisions and behaviors are driven by a combination of different factors and motivations that need to be weighed and balanced. For example, a person who chooses a very high standard of living requiring intense energy consumption will experience immediate personal benefits (life comfort), while in the long run causing disadvantages both for the individual and at the group level (need for high energy production, potential energy shortages, environmental damage). However, giving up on a high standard of living to save energy will initially lead mainly to personal disadvantages (loss of comfort), with positive outcomes experienced by society only in the long run. The immediate incentive structure thus will not motivate a self-interested individual to reduce energy consumption (as long as the energy prices are held constant). Nevertheless, recent economic work has demonstrated that individuals are actually willing to sacrifice their immediate benefits in order to promote behavior that is beneficial for the group in the long run (Fehr and Gachter, 2002). Importantly, neuroimaging results indicate that the trade-off of immediate individual gain for the long-term advantage of the group is driven by neural regions involved in the experience of reward and emotions (Sanfey et al., 2003; de Quervain et al., 2004). These results not only indicate the potential importance of considering emotions in the governance of public goods such as unmined energy resources and clean air, but also open up a path for the integration of energy conservation into classic economic perspectives: emotional reactions may actually add utility value to energy conservation. The appraisalemotion model specifies a sparse set of appraisals that underlie the elicitation of individual emotional responses in the energy domain. It may be a promising approach to develop interventions targeting the specific set of appraisal criteria proposed here. Modifying an individual's appraisal of the implications of energy overconsumption, for example through targeted information provision campaigns, may change his/her emotional response, which may in turn increase the utility value for certain decision options, either via immediate emotions or anticipated emotions. This may be an avenue to integrate affective processing and emotions into economical and psychological rational choice models based on utility and self-interested considerations such as the TPB.

Normative models such as the VBN already include core values, which play an important role in the elicitation of emotions (Nelissen et al., 2007; Brosch and Sander, 2013a) and their role in decision-making (Brosch and Sander, 2013b), as well as moral emotions such as guilt or shame that serve to motivate the normative function of social constraints. In this perspective, environmental-friendly behavior seems to be conceptualized as "morally correct" behavior, that is, people save energy to avoid violating a social norm, resulting in real or imagined social disapproval and feelings of guilt. Affect motivates decisions and behaviors insofar as individuals are trying to prevent negative outcomes. However, that is only "half the truth" about the motivating function of emotions. Emotions also motivate to promote positive outcomes, strive for reward, attain goals, and self-actualize (Higgins, 1998). Thus, a more complete integration of affective processes into this kind of theory may capitalize on the full range of human emotions. Interventions may aim at combining 
desired behaviors both with positive incentives that individuals want to attain and with negative outcomes that individuals want to prevent. For example, information campaigns or advertising campaigns for energy-efficient products may include material that emphasizes the positive emotions resulting from environmentally responsible behavior (e.g., pride), while also mentioning the potentially aversive consequences of environmental damage.

A perspective that considers emotions as yielding useful, "rational" information may furthermore fruitfully be linked to approaches from behavioral economics that focus on heuristics and cognitive biases and their impact on decision-making. In fact, at least two heuristics that are central to this perspective can be linked to affective processing. The affect heuristic describes the observation that an individual may substitute an initial affective reaction for a thorough analysis of the situation (Finucane et al., 2000). For example, participants who were asked to evaluate the potential risks and benefits of nuclear energy showed a strong negative correlation between their risk and benefits judgments, especially when acting under time pressure, which was interpreted as the impact of a rapid affective response to the evaluated stimulus that participants used to inform both kinds of judgments. The availability heuristic refers to the fact that information that is easily retrievable from memory is especially influential during a decision process (Tversky and Kahneman, 1973). Whereas both types of heuristics are usually discussed in a dual process framework that opposes intuitive/affective responses to rational thought, we have outlined above that recent psychological and neuroscientific research suggests a revision of this perspective (e.g., Damasio, 1994). Even rapid affective responses based on fast, automatic appraisal processes may contain useful information that can improve decision-making, and thus should not be opposed to rational processes (see Brosch, 2013, for a more detailed discussion). Furthermore, it has been shown that information that has previously been appraised as relevant for one's concerns is prioritized in memory and thus more easily retrievable (Montagrin et al., 2013). As such, it seems highly adaptive that information that was relevant in the past should have a larger impact on current decision-making (Phelps and Sharot, 2008). Interventions that aim at nudging people toward desired outcomes (Thaler and Sunstein, 2008) should take into account the possibility to leverage rapid automatic appraisal processes by appropriately framing the decision situation. For example, in a recent study household energy use was reduced and kept below average by combining information about consumption patterns with minimal affective information (a smiley face for households using less than average energy, see Schultz et al., 2007).

Thus, taking into account affective processes and emotions related to energy conservation (or the lack of energy conservation) may not only substantially increase our understanding of the mechanism that underlie individual decisions and behaviors related to energy use, but may also be successfully integrated with and complement other existing perspectives in the behavioral sciences, contributing to the interdisciplinarity that is required for the development of efficient interventions.

One qualification of the work presented here is that the evidence supporting the appraisal-emotion model so far is based exclusively on self-report measures, i.e., participants were asked to report their appraisal structure and to remember their emotional experience in relevant situations. This is problematic both for methodological and conceptual reasons. At the methodological level, participants may have been prone to a number of response biases that come with the self-report format. For example, participants may have been motivated to respond in a manner that will be viewed favorably by others and thus exaggerated their intentions to reduce energy use, or in a manner coherent with their personal theories about emotion and thus exaggerated the link between appraisals, emotions, and decisions. However, this problem is shared by most empirical research in this field, which, given the variables that researchers are interested in, is strongly based on self-report and questionnaire data. An important next research step will be to link individual appraisal structures and emotions not only to intentions to reduce energy use, but also to objective measures of actual behavior (e.g., actual energy use). At the conceptual level, psychological and neuroimaging research has shown that the appraisal process occurs very rapidly and in a partially automatic fashion (Grandjean and Scherer, 2008; Brosch and Sander, 2013a). Thus, not all aspects of the appraisal process are necessarily accessible to introspection and can be reported in a questionnaire. The aspects of appraisal that reach consciousness may only represent the "tip of the iceberg" (Scherer, 2005). This issue needs to be tackled by combining multiple methods over and above self-report, such as the measurement of energyrelated appraisal processes at the neural level and an assessment of the different components of the emotional response as it occurs, including physiological responses and elicited action tendencies.

Considering automatic affective processes in energy-relevant situations may furthermore vastly improve our understanding of the mechanisms underlying habits, automatized behaviors which are also very important determinants of energy use (Marechal, 2009), but are driven by mechanisms different from the ones underlying more deliberate decision-making (Aarts and Dijksterhuis, 2000). Thus, complementing standard self-report measures with implicit tasks and neuroimaging methods seems an especially promising approach to develop more complete models of energyrelated decision-making and behavior and may well become the future gold standard.

To sum up, in this contribution we argue for an integration of affective processes and emotions into the study of energy-related decisions and behavior. In contrast to theories that consider emotions as "irrational interference," we emphasize that cognitive and affective processes are closely intertwined. Emotional responses represent important information about the relevance of an object or situation for an individual's concerns, goals, needs, and values. They may thus play an important and adaptive role in driving individual decisions and behaviors, over and above considerations of utility, beliefs, and behavioral norms. A sparse set of factors assessing an individual's appraisal processes and emotional response patterns with regards to energy-relevant situations can predict a sizeable amount of variance in intentions to reduce energy use. Importantly, a comparison with two established models shows that the appraisal-emotion approach can explain variance over and above models focusing on self-interest and normative considerations, respectively. We argue that affective processes and emotions can and should be integrated into other theoretical perspectives 
developed within the behavioral sciences that are important in research on energy use. Energy-related decisions and behaviors are manifold. A thorough understanding of the underlying mechanisms requires the simultaneous consideration of the decision situation with its specific incentive structure, the decider with his or her beliefs, values, appraisals, and emotions, and the type of decision, ranging from highly deliberate informed choices to habitual behaviors.

A better understanding of the factors influencing individual energy-related decisions and behaviors is important for a successful energy transition, and thus of high societal interest. Over the last two decades, the "affective turn" has fundamentally changed the way psychologists and neuroscientists think about emotions, their adaptive function, and their role in decision-making. We hope that the research and the open questions outlined here will contribute to an integration of these ideas into research on one of society's fundamental problems.

\section{REFERENCES}

Aarts, H., and Dijksterhuis, A. (2000). Habits as knowledge structures: automaticity in goal-directed behavior. J. Pers. Soc. Psychol. 78, 53-63. doi:10.1037/0022-3514. 78.1 .53

Abrahamse, W., and Steg, L. (2009). How do socio-demographic and psychological factors relate to households' direct and indirect energy use and savings? J. Econ. Psychol. 30, 711-720. doi:10.1016/j.joep.2009.05.006

Abrahamse, W., and Steg, L. (2011). Factors related to household energy use and intention to reduce it: the role of psychological and socio-demographic variables. Hum. Ecol. Rev. 18, 30-40.

Ajzen, I. (1991). The theory of planned behavior. Organ. Behav. Hum. Decis. Process 50, 179-211. doi:10.1016/0749-5978(91)90020-T

Armitage, C. J., and Conner, M. (2001). Efficacy of the theory of planned behaviour: a meta-analytic review. Br. J. Soc. Psychol. 40, 471-499. doi:10.1348/ 014466601164939

Bamberg, S., Ajzen, I., and Schmidt, P. (2003). Choice of travel mode in the theory of planned behavior: the roles of past behavior, habit, and reasoned action. Basic Appl. Soc. Psych. 25, 175-187. doi:10.1207/S15324834BASP2503_01

Bechara, A., Damasio, H., Tranel, D., and Damasio, A. R. (1997). Deciding advantageously before knowing the advantageous strategy. Science 275, 1293-1295. doi:10.1126/science.275.5304.1293

Bechara, A., Damasio, H., Tranel, D., and Damasio, A. R. (2005). The Iowa Gambling Task and the somatic marker hypothesis: some questions and answers. Trends Cogn. Sci. 9, 159-162. doi:10.1016/j.tics.2005.02.002

Becker, G. S. (1976). The Economic Approach to Human Behavior. Chicago: University of Chicago Press.

Brosch, T. (2013). On the role of appraisal processes in the construction of emotion. Emot. Rev. 5, 369-373. doi:10.1177/1754073913489752

Brosch, T., and Sander, D. (2013a). The appraising brain: towards a neurocognitive model of appraisal processes in emotion. Emot. Rev. 5, 163-168. doi: $10.1177 / 1754073912468298$

Brosch, T., and Sander, D. (2013b). Neurocognitive mechanisms underlying valuebased decision-making: from core values to economic value. Front. Hum. Neurosci. 7:398. doi:10.3389/fnhum.2013.00398

Brosch, T., Scherer, K. R., Grandjean, D., and Sander, D. (2013). The impact of emotion on perception, attention, memory, and decision-making. Swiss Med. Wkly. 143, w13786. doi:10.4414/smw.2013.13786

Cialdini, R. B. (2009). Influence: Science and Practice. Boston: Allyn \& Bacon.

Damasio, A. R. (1994). Descartes' Error: Emotion, Reason, and the Human Brain. New York: Putnam Publishing.

Davidson, R. J., Scherer, K. R., and Goldsmith, H. H. (2003). Handbook of Affective Sciences. New York: Oxford University Press.

de Quervain, D. J., Fischbacher, U., Treyer, V., Schellhammer, M., Schnyder, U., Buck, A., et al. (2004). The neural basis of altruistic punishment. Science 305, 1254-1258. doi:10.1126/science. 1100735
Dunlap, R. E., Van Liere, K. D., Mertig, A. G., and Jones, R. E. (2000). Measuring endorsement of the new ecological paradigm: a revised NEP scale. J. Soc. Issues 56, 425-442. doi:10.1111/0022-4537.00176

Ellsworth, P., and Scherer, K. R. (2003). "Appraisal processes in emotion," in Handbook of Affective Sciences, eds R. J. Davidson, H. H. Goldsmith, and K. R. Scherer (Oxford: Oxford University Press), 572-595.

Fehr, E., and Gachter, S. (2002). Altruistic punishment in humans. Nature 415, 137-140. doi:10.1038/415137a

Finucane, M. L., Alhakami, A., Slovic, P., and Johnson, S. M. (2000). The affect heuristic in judgments of risks and benefits. J. Behav. Decis. Mak. 13, 1-17. doi:10.1002/(SICI)1099-0771(200001/03)13:1C1::AID-BDM3333.0.CO;2-S

Gentsch, K., Grandjean, D., and Scherer, K. R. (2013). Temporal dynamics of event-related potentials related to goal conduciveness and power appraisals. Psychophysiology 50, 1010-1022. doi:10.1111/psyp.12079

Goldie, P. (ed.) (2010). The Oxford Handbook of Philosophy of Emotion. New York: Oxford University Press.

Grandjean, D., and Scherer, K. R. (2008). Unpacking the cognitive architecture of emotion processes. Emotion 8, 341-351. doi:10.1037/1528-3542.8.3.341

Guagnano, G. A., Stern, P. C., and Dietz, T. (1995). Influences on attitude-behavior relationships - a natural experiment with curbside recycling. Environ. Behav. 27, 699-718. doi:10.1177/0013916595275005

Han, S., and Lerner, J. S. (2009). “Decision making," in The Oxford Companion to the Affective Sciences, eds D. Sander and K. R. Scherer (New York: Oxford University Press), 111-113.

Harland, P., Staats, H., and Wilke, H. A. M. (1999). Explaining proenvironmental intention and behavior by personal norms and the theory of planned behavior. J. Appl. Soc. Psychol. 29, 2505-2528. doi:10.1111/j.1559-1816.1999.tb00123.x

Higgins, E. T. (1998). Promotion and prevention: regulatory focus as a motivational principle. Adv. Exp. Soc. Psychol. 30, 1-46. doi:10.1016/S0065-2601(08)60381-0

Kahneman, D. (2003). Maps of bounded rationality: psychology for behavioral economics. Am. Econ. Rev. 93, 1449-1475. doi:10.1257/000282803322655392

Kals, E., and Muller, M. M. (2012). "Emotions and environment," in The Oxford Handbook of Environmental and Conservation Psychology, ed. S. D. Clayton (New York: Oxford University Press), 128-147.

Kals, E., Schumacher, D., and Montada, L. (1999). Emotional affinity toward nature as a motivational basis to protect nature. Environ. Behav. 31, 178-202. doi:10.1177/00139169921972056

Kreibig, S. D. (2010). Autonomic nervous system activity in emotion: a review. Biol. Psychol. 84, 394-421. doi:10.1016/j.biopsycho.2010.03.010

Lindenberg, S., and Steg, L. (2007). Normative, gain and hedonic goal frames guiding environmental behavior. J. Soc. Issues 63, 117-137. doi:10.1111/j.1540-4560. 2007.00499.x

Marechal, K. (2009). An evolutionary perspective on the economics of energy consumption: the crucial role of habits. J. Econ. Issues 43, 69-88. doi:10.2753/ JEI0021-3624430104

Marsh, P., and Collett, P. (1986). Driving Passion: The Psychology of the Car. London: Cape.

Montagrin, A., Brosch, T., and Sander, D. (2013). Goal conduciveness as a key determinant of memory facilitation. Emotion 13, 622-628. doi:10.1037/a0033066

Moors, A. (2010). Automatic constructive appraisal as a candidate cause of emotion. Emot. Rev. 2, 139-156. doi:10.1177/1754073909355012

Nelissen, R. M. A., Dijker, A. J. M., and de Vries, N. K. (2007). Emotions and goals: assessing relations between values and emotions. Cogn. Emot. 21, 902-911. doi:10.1080/02699930600861330

Nordlund, A. M., and Garvill, J. (2003). Effects of values, problem awareness, and personal norm on willingness to reduce personal car use. J. Environ. Psychol. 23, 339-347. doi:10.1016/S0272-4944(03)00037-9

Phelps, E. A., and Sharot, T. (2008). How (and why) emotion enhances the subjective sense of recollection. Curr. Dir. Psychol. Sci. 17, 147-152. doi:10.1111/j. 1467-8721.2008.00565.x

Poortinga, W., Steg, L., and Vlek, C. (2004). Values, environmental concern, and environmental behavior - a study into household energy use. Environ. Behav. 36, 70-93. doi:10.1177/0013916503251466

Poortinga, W., Steg, L., Vlek, C., and Wiersma, G. (2003). Household preferences for energy-saving measures: a conjoint analysis. J. Econ. Psychol. 24, 49-64. doi:10.1016/S0167-4870(02)00154-X

Samuelson, W., and Zeckhauser, R. (1988). Status quo bias in decision making. J. Risk Uncertain 1, 7-59. doi:10.1007/BF00055564 
Sander, D. (2013). "Models of emotion: the affective neuroscience approach," in Handbook of Human Affective Neuroscience, eds J. L. Armony and P. Vuilleumier (Cambridge: Cambridge University Press), 5-53.

Sander, D., and Scherer, K. R. (eds). (2009). Oxford Companion to Emotion and the Affective Sciences. New York: Oxford University Press.

Sanfey, A. G., Rilling, J. K., Aronson, J. A., Nystrom, L. E., and Cohen, J. D. (2003). The neural basis of economic decision-making in the Ultimatum Game. Science 300, 1755-1758. doi:10.1126/science.1082976

Scherer, K. R. (2005). "Unconscious processes in emotion: the bulk of the iceberg," in The Unconscious in Emotion, eds P. M. Niedenthal, L. Feldman-Barrett, and P. Winkielman (New York: Guilford), 312-334.

Scherer, K. R. (2009). The dynamic architecture of emotion: evidence for the component process model. Cogn. Emot. 23, 1307-1351. doi:10.1080/ 02699930902928969

Schultz, P. W., Nolan, J. M., Cialdini, R. B., Goldstein, N. J., and Griskevicius, V. (2007). The constructive, destructive and reconstructive power of social norms. Psychol. Sci. 18, 429-434. doi:10.1111/j.1467-9280.2007.01917.x

Schwartz, S. H. (1977). "Normative influences on altruism," in Advances in Experimental Social Psychology, Vol. 10, ed. L. Berkowitz (New York: Academic Press), 221-279.

Schwartz, S. H. (1992). "Universals in the content and structure of values: theoretical advances and empirical tests in 20 countries," in Advances in Experimental Social Psychology, Vol. 25, ed. M. P. Zanna (San Diego, CA: Academic Press), 1-65.

Siemer, M., Mauss, I., and Gross, J. J. (2007). Same situation - different emotions: how appraisals shape our emotions. Emotion 7, 592-600. doi:10.1037/1528-3542. 7.3.592

Stern, N. (2007). Economics of Climate Change - The Stern Review. Cambridge: Cambridge University Press.

Stern, P. C. (2000). Toward a coherent theory of environmentally significant behavior. J. Soc. Issues 56, 407-424. doi:10.1111/0022-4537.00175

Sutterlin, B., Brunner, T. A., and Siegrist, M. (2011). Who puts the most energy into energy conservation? A segmentation of energy consumers based on energyrelated behavioral characteristics. Energy Policy 39, 8137-8152. doi:10.1016/j. enpol.2011.10.008
Thaler, R. H., and Sunstein, C. R. (2008). Nudge: Improving Decisions About Health, Wealth, and Happiness. Yale: Yale University Press.

Tietenberg, T. (1990). Economic Instruments for Environmental Regulation. Oxford: Oxford University Press.

Triandis, H. C. (1977). Interpersonal Behavior. Monterey, CA: Brooks/Cole Publishing Company.

Tversky, A., and Kahneman, D. (1973). Availability - heuristic for judging frequency and probability. Cogn. Psychol. 5, 207-232. doi:10.1016/0010-0285(73)90033-9

Tversky, A., and Kahneman, D. (1981). The framing of decisions and the psychology of choice. Science 211, 453-458. doi:10.1126/science.7455683

Vuilleumier, P., and Brosch, T. (2009). "Interactions of emotion and attention," in The Cognitive Neurosciences IV, ed. M. S. Gazzaniga (Cambridge: MIT Press), 925-934.

Wilson, C., and Dowlatabadi, H. (2007). Models of decision making and residential energy use. Annu. Rev. Environ. Resour. 32, 169-203. doi:10.1146/annurev. energy.32.053006.141137

Conflict of Interest Statement: The authors declare that the research was conducted in the absence of any commercial or financial relationships that could be construed as a potential conflict of interest.

Received: 15 January 2014; paper pending published: 17 February 2014; accepted: 04 March 2014; published online: 17 March 2014.

Citation: Brosch T, Patel MK and Sander D (2014) Affective influences on energyrelated decisions and behaviors. Front. Energy Res. 2:11. doi: 10.3389/fenrg.2014.00011 This article was submitted to Energy Systems and Policy, a section of the journal Frontiers in Energy Research.

Copyright (C) 2014 Brosch, Patel and Sander. This is an open-access article distributed under the terms of the Creative Commons Attribution License (CC BY). The use, distribution or reproduction in other forums is permitted, provided the original author(s) or licensor are credited and that the original publication in this journal is cited, in accordance with accepted academic practice. No use, distribution or reproduction is permitted which does not comply with these terms. 